\title{
Prediction of Turbulent Jet Mixing Noise Reduction by
}

\section{Water Injection}

\author{
Max Kandula ${ }^{1}$ \\ ASRC Aerospace, NASA Kennedy Space Center, Florida 32899, USA
}

\begin{abstract}
A one-dimensional control volume formulation is developed for the determination of jet mixing noise reduction due to water injection. The analysis starts from the conservation of mass, momentum and energy for the control volume, and introduces the concept of effective jet parameters (jet temperature, jet velocity and jet Mach number). It is shown that the water to jet mass flow rate ratio is an important parameter characterizing the jet noise reduction on account of gas-to-droplet momentum and heat transfer. Two independent dimensionless invariant groups are postulated, and provide the necessary relations for the droplet size and droplet Reynolds number. Results are presented illustrating the effect of mass flow rate ratio on the jet mixing noise reduction for a range of jet Mach number and jet Reynolds number. Predictions from the model show satisfactory comparison with available test data on perfectly expanded hot supersonic jets. The results suggest that significant noise reductions can be achieved at increased flow rate ratios.
\end{abstract}

\footnotetext{
' Subject Matter Expert, Mailstop ASRC-5211, Associate Fellow AIAA.
} 


\section{Nomenclature}

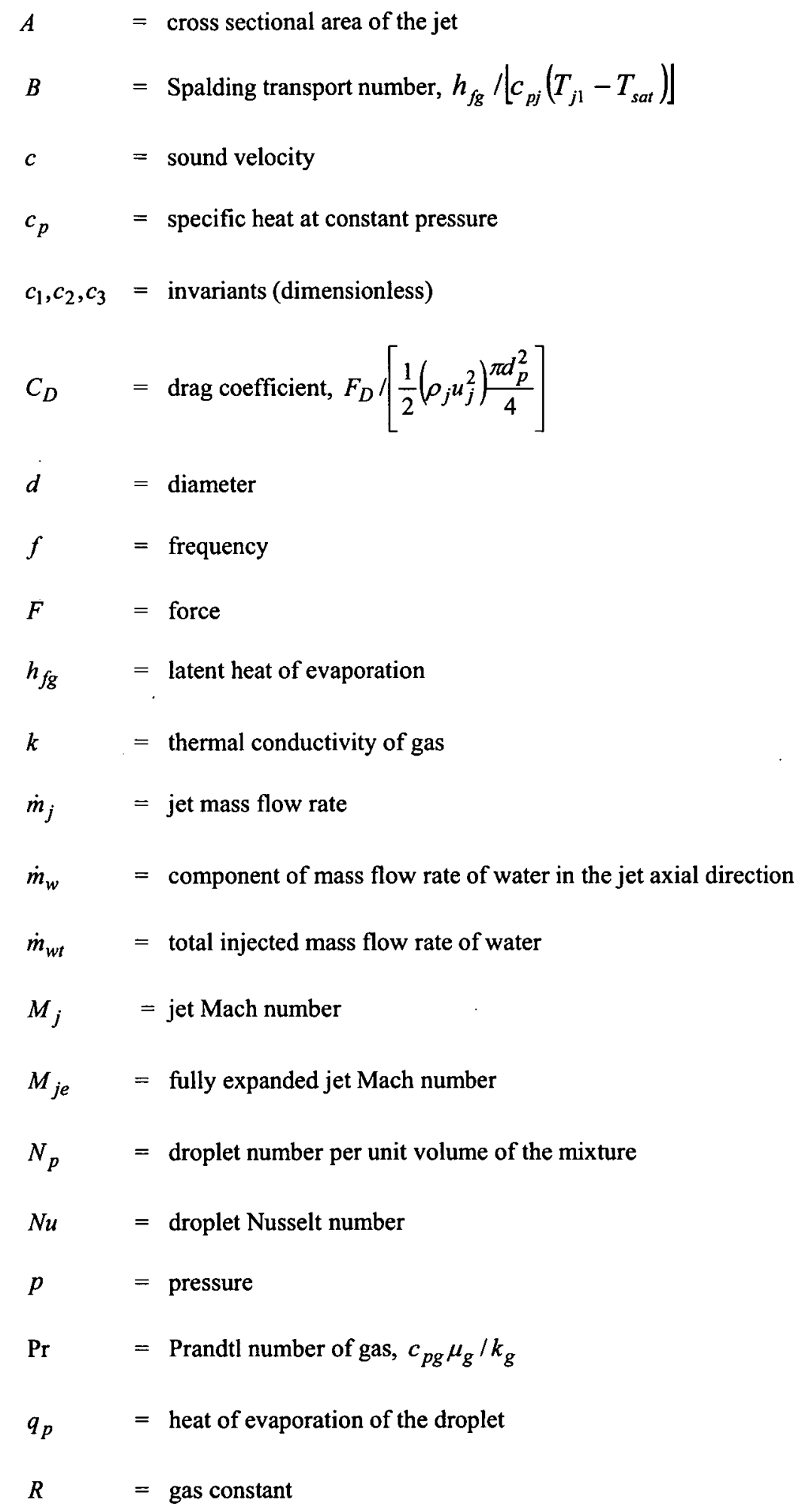




$$
\begin{array}{ll}
\operatorname{Re}_{j} & =\text { jet exit Reynolds number, } \rho_{j 1} u_{j 1} d_{j 1} / \mu_{j 1} \\
\operatorname{Re}_{p} & =\text { droplet Reynolds number, } \rho_{j 1}\left|u_{j 1}-u_{p}\right| d_{p} / \mu_{j 1} \\
S P L & =\text { sound pressure level } \\
T & =\text { temperature } \\
T_{j e} & =\text { equivalent gas temperature for heat transfer } \\
u & =\text { velocity in the streamwise direction } \\
x & =\text { axial distance from the nozzle exit plane } \\
x_{t} & =\text { length of potential core in the jet }
\end{array}
$$

\section{Greek Symbols}

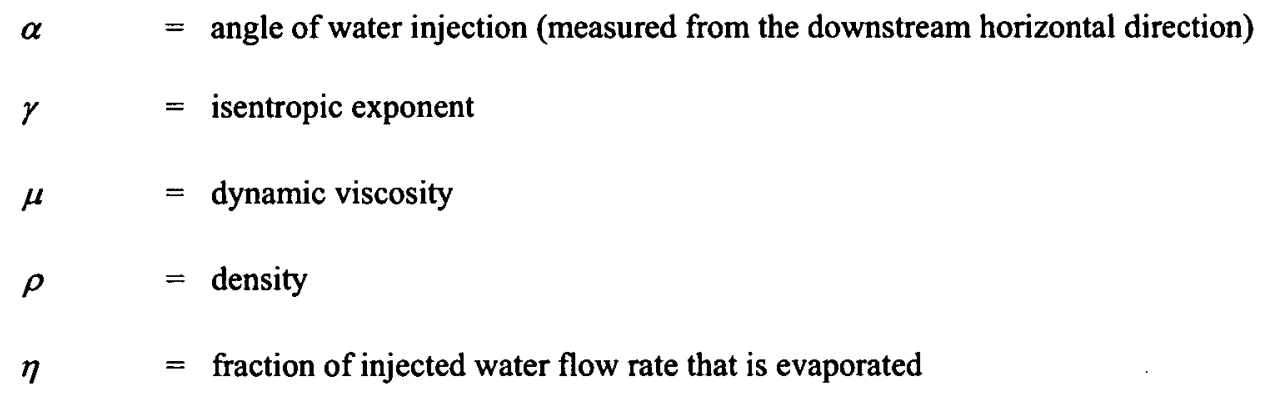

\section{Subscripts}

$\begin{array}{ll}a & =\text { ambient fluid } \\ c r & =\text { critical } \\ D & =\text { drag } \\ g & =\text { gas } \\ j & =\text { jet } \\ l & =\text { liquid } \\ p & =\text { droplet (or particle) } \\ \text { sat } & =\text { saturation } \\ t & =\text { stagnation }\end{array}$


$w \quad=$ injected water

$1=$ jet exit

$2=$ effective jet property 


\section{Introduction}

Three distinct components of noise are present in supersonic jets: turbulent mixing noise, Mach wave radiation, and broadband shock noise, see Crighton [1]. While the broadband shock noise (emanating from shock-turbulence interaction) is associated with imperfectly expanded jets, the turbulent mixing noise generally represents the dominant component of supersonic jet noise to the overall sound pressure level (OASPL), with the Mach wave radiation (caused by the supersonic convection of turbulent eddies with respect to the ambient fluid) contributing significant noise in the peak radiation direction. The high noise levels ( 160 to $170 \mathrm{~dB}$ ) radiated by launch vehicles at lift-off induce severe vibration on the launch vehicle structure, payload, and ground support equipment.

Water injection has been traditionally considered for the suppression of high noise levels from rocket exhausts in launch vehicle environments. For example, large amounts of water (of the order of $300,000 \mathrm{gpm}$ ) are used for the suppression of ignition overpressure (IOP) and lift-off noise during Space Shuttle launches. The water mass flow rate to the SRB (Solid Rocket Booster) exhaust mass flow rate ratio is maintained around one to two in order to meet payload design requirements of $145 \mathrm{~dB}$ (Dougherty \& Guest [2], Jones [3]). Water injection could reduce noise by as much as $8-12 \mathrm{~dB}[2,3]$. Such a high level of reduction includes reductions in the turbulent mixing noise and the broadband shock noise, the latter representing the predominant component of noise reduction.

Water injection mitigates all the three components of jet noise: the turbulent mixing noise, the Mach wave radiation, and the broadband shock noise. Two principal mechanisms leading to the diminution of jet noise by water injection are the reduction of jet velocity and jet temperature (Moriniere, Gervais and Peube [4]). The decrease of jet velocity is occasioned through momentum transfer between the liquid and the gaseous phases, and the reduction of the jet temperature is achieved due to partial vaporization of the injected water (Zoppellari and Juve $[5,6])$. The

effect of water may also be regarded as effectively increasing the effective jet density (Jones [3]). Important velocity reductions are achieved within a few diameters of the nozzle exit. Noise reductions of the order of $10 \mathrm{~dB}$ are realized for both cold and hot jets $[5,6]$.

Several design parameters influence the effectiveness of noise reduction by water injection. These include water to jet mass flow rate ratio, axial injection location, water injection angle, number of injectors, method of injection (jet type or spray type), droplet size, water pressure, and water temperature. Optimal injection parameters need to be 
determined for the design of efficient water injection system. Data of Zoppellari and Juve [5] and of Norum [7] suggest that the best noise reductions of the order of 10 to $12 \mathrm{~dB}$ are obtained at injection angles of 45 to $60 \mathrm{deg}$., injection near the nozzle exit (especially for shock-containing jets), and high mass flow rates. Also the optimum number of injectors appears to be around eight. Experiments by Krothappalli et al. [8], Greska and Krothapalli [9] and Washington and Krothapalli [10] at reduced water mass flow rate ratios (about 0.1) through the use of microjets show sizable noise reduction for application to aircraft jet engines. The noise reduction with microjet injection is shown to be achieved primarily through reduced turbulence in the carrier gas, while the mean velocity field remains essentially unaltered.

Experiments with water injection suggest that the mass flow rate ratio appears to be an important parameter. Tests conducted with water to jet mass flow rate ratios up to four (Zoppellari and Juve [5]) reveal that significant noise reductions can be achieved at high water flow rate ratio. In the case of cold jets, beyond a critical mass flow rate ratio, the velocity reduction and thus the noise reduction is small. For hot jets, only a fraction of the liquid is effective in reducing the air jet velocity due to drop evaporation. At low water flow rates, it is possible to reduce the shock associated noise significantly.

At considerably high mass flow rates, the benefit of velocity reduction of the air jet by momentum transfer between the two phases is partly opposed by the emergence of new parasitic sources linked to water injection, which include the impact noise of air on the water jets, fragmentation of these water jets, and unsteady movement of the droplets. A compromise can be found between significant penetration of water jet into the air jet and low impact noise. A significant parameter is the velocity component of water jets that is perpendicular to the air jet. If this component is high, water penetrates deeply into the air jet and mixing takes place rapidly. If this component is small, water does not produce significant drag and impact noise.

On the theoretical front, studies on the effect of water droplets on noise reduction are very few, and these are concerned primarily with plane waves. Sound attenuation studies in a two-phase medium originated from the work of Sewell [11] on the assumption of immovable particles. Epstein and Carhart [12] considered sound attenuation by particles, allowing the particles to oscillate and considering both momentum and heat exchange. They compared the theory with the measurements with water droplets by Knudsen et al. [13]. Marble et al. [14, 15] conducted theoretical investigations to determine the sound attenuation in fans and ducts by vaporization of liquid droplets. For plane waves (Marble and Candel [15]), the attenuation magnitude is shown to exceed $5 \mathrm{~dB} / \mathrm{m}$ at $25 \mathrm{C}$ with a cloud of 
$0.7 \mu \mathrm{m}$ radius droplets constituting $1 \%$ of the gas mixture (see, Krothapalli et al. [16]). Temkin and Dobbins [17] presented a classical study of both attenuation and dispersion of sound by spherical droplets, considering the particulate relaxation processes of momentum and heat transport. Dupays and Vuillot [18] extended the analysis of Temkin and Dobbins [17] to accommodate the effects of droplet evaporation and combustion. Unfortunately, these results are not directly applicable to the study of turbulent mixing noise attenuation in jets.

In view of the importance of water injection in jet noise suppression, a theoretical understanding of the mechanism of noise reduction is useful in the design and optimization of water injection systems for launch acoustics application. To the author's knowledge, theoretical studies addressing the effect of water injection in mitigating jet mixing noise have not been previously reported. It is the purpose of this paper to develop a simple one-dimensional analytical model for estimating the jet mixing noise suppression due to water injection. The proposed model will be compared with existing data on jet noise. This article is based primarily on ref. [19].

\section{ANALYSIS}

\section{A. Control Volume Formulation and Conservation Equations}

The governing equations of continuity, momentum and energy for the control volume (Fig. 1) are expressed as

$$
\begin{gathered}
\rho_{j 1} u_{j 1} A_{j 1}=\rho_{j 2} u_{j 2} A_{j 2}-\eta \dot{m}_{w} \\
\rho_{j 2} u_{j 2}^{2} A_{j 2}-\rho_{j 1} u_{j 1}^{2} A_{j 1}=-F_{d}+\eta \dot{m}_{w} u_{p} \\
\dot{m}_{j 2}\left(c_{p j} T_{j 2}+\frac{u_{j 2}^{2}}{2}\right)=\dot{m}_{j 1}\left(c_{p j} T_{j 1}+\frac{u_{j 1}^{2}}{2}\right)-F_{d} u_{p}+\eta \dot{m}_{w} T_{p} c_{p l}
\end{gathered}
$$

In the above equations, $\dot{m}_{w}$ is the mass flow rate of water in the jet axial direction, $\eta$ the fraction of the injected water flow rate that is evaporated, $F_{d}$ the drag force of droplets, $u_{p}$ the droplet velocity. The subscripts land 2 refer to the inlet and exit states of the control volume under consideration.

The quantity $\dot{m}_{w}$ is related to the total injected water flow rate $\dot{m}_{w t}$ as

$$
m_{w}=m_{w t} \cos \alpha
$$

where $\alpha$ represents the angle of injection (measured from the downstream axis). 


\section{B. Physical Assumptions}

The following physical assumptions are made in the analysis. Many of these assumptions are typically considered in droplet transport models for the theoretical investigation of dispersed droplet dynamics, heat transfer and combustion with applications to spray cooling $[20,21]$ and turbulent diffusion of droplets.

a. The pressure in the jet is constant. This approximation is appropriate for perfectly expanded supersonic jets, where turbulent mixing is a major noise component.

b. The gas and gas-vapor mixture obey perfect gas law (calorically and thermally perfect). The equation of state for a perfect gas is expressed by

$$
\rho_{j 1} R_{j 1} T_{j 1}=\rho_{j 2} R_{j 2} T_{j 2}
$$

c. The gas constant for the gas and the gas-water vapor mixture is approximately the same.

d. The droplets are uniformly distributed in the gas mixture in the control volume.

e. The droplet size is uniform. In reality, the atomization produces a drop size distribution (such as lognormal), and an appropriate characteristic drop diameter (such as Sauter mean diameter $d_{32}$ ) may represent drop drag and heat transfer more accurately. Also, the droplet size diminishes as it traverses downstream through the control volume due to evaporation.

f. The drop temperature is uniform (assumption of infinite thermal diffusivity), and is at the saturation state. Thus

$$
T_{p}=T_{\text {sat }}
$$

The uniform temperature model belongs to one of the limiting cases of transport processes (Faeth [20]) in evaporating and combusting sprays.

g. Thermal properties of the gas and water are independent of temperature.

h. The droplet drag and heat transfer are approximated by existing semi-empirical relations.

i. The axial extent of the control volume is taken as two jet diameters $\left(n=L / d_{j}=2\right)$ in order to ensure that the effective jet properties due to water injection are representative. For comparison purposes, the length of the potential core $x_{t}$ in chemical rockets follows closely the empirical relation of the form (Eldred [22])

$$
\frac{x_{t}}{d_{j 1}}=3.45\left(1+0.38 M_{j e}\right)^{2}
$$


where $M_{j e}$ stands for the fully expanded jet Mach number. The largest noise-producing region in the jet is known to exist at the end of the potential core. According to [23, 24], the maximum intensity of the acoustic sources in a supersonic jet is generally located between 8 and 10 jet diameters.

j. Droplet evaporation is controlled by heat transfer from the gas to the droplets (thermal conductivity-controlled), as opposed to diffusion-controlled (Dupays and Vuillot [18]). This assumption appears reasonable for hot jets at relatively high temperature (typical of rocket exhausts) under investigation. For cold jets, mass transfer by diffusion can become important, with the driving potential represented by the difference between vapor pressure at the droplet surface and the partial pressure of the vapor in the bulk gas.

k. The droplets are assumed to be rigid (no surface tension effects; no deformation) and spherical.

1. Radiative heat transfer from the drop and the gas is neglected.

m. Parasitic noise generation due to water impact and breakup is not accounted for.

\section{Solution}

With the above assumptions, Eqs. (1), (2), (3) and (5) are now solved for the effective jet circumstances at the downstream section 2 of the control volume. A closed form solution is thereby obtained as follows.

\section{Effective Jet Velocity}

From the momentum equation in conjunction with the continuity equation, an expression of the jet velocity ratio can be obtained as:

$$
\frac{u_{j 2}}{u_{j 1}}=\frac{1}{\left(1+\eta \frac{\dot{m}_{w}}{\dot{m}_{j 1}}\right)}\left[1-\frac{F_{D}}{\rho_{j 1} u_{j 1}^{2} A_{j 1}}+\frac{\eta \dot{m}_{w} u_{p}}{\rho_{j 1} u_{j 1}^{2} A_{j 1}}\right]
$$

The second term in the parenthesis on the RHS can be expressed as

$$
\begin{gathered}
\phi=\frac{F_{D}}{\rho_{j 1} u_{j 1}^{2} A_{j 1}}=N_{p} C_{D}\left(\frac{A_{p}}{A_{j 1}}\right) \frac{1}{2}\left(1-\frac{u_{p}}{u_{j 1}}\right)^{2} \\
N_{p}=\frac{3}{2}\left(\frac{\dot{m}_{w}}{\dot{m}_{j 1}}\right)\left(\frac{\rho_{j 1}}{\rho_{p}}\right)\left(\frac{d_{j 1}}{d_{p}}\right)^{3} n(1-\eta)
\end{gathered}
$$

denotes the number of droplets per unit volume of the gaseous mixture in the control volume. The quantity $d_{p}$ stands for the droplet diameter, and $n=L / d_{j}$. The quantity $\phi$ can be expressed as 


$$
\phi=\psi\left(\dot{m}_{w} / \dot{m}_{j 1}\right)(1-\eta)
$$

where

$$
\psi=\frac{3}{2}\left(\frac{\rho_{j 1}}{\rho_{p}}\right)\left(\frac{d_{j 1}}{d_{p}}\right)^{3} n \frac{1}{2} C_{D}\left(\frac{\operatorname{Re}_{p}}{\operatorname{Re}_{j 1}}\right)^{2}
$$

The third term on the RHS can be written as

$$
\frac{\eta \dot{m}_{w} u_{p}}{\rho_{j 1} u_{j 1}^{2} A_{j 1}}=\eta\left(\frac{\dot{m}_{w}}{\dot{m}_{j 1}}\right)\left[1-\frac{\operatorname{Re}_{p}}{\operatorname{Re}_{j 1}} \frac{d_{j 1}}{d_{p}}\right]
$$

where $\operatorname{Re}_{j 1}$ is the jet Reynolds number, and $\operatorname{Re}_{p}$ the droplet Reynolds number defined by

$$
\operatorname{Re}_{j 1}=\frac{\rho_{j 1} u_{j 1} d_{j 1}}{\mu_{j 1}}, \quad \operatorname{Re}_{p}=\frac{\rho_{j 1}\left(u_{j 1}-u_{p}\right) d_{p}}{\mu_{j 1}}
$$

\section{Effective Jet Temperature}

Consideration of the energy equation in conjunction with the equation of state furnishes the relation for the effective jet temperature

$$
\frac{T_{j 2}}{T_{j 1}}=\frac{1}{\left(1+\eta \frac{\dot{m}_{w}}{\dot{m}_{j 1}}\right)}\left[1+\frac{u_{j 1}^{2}}{2 c_{p j} T_{j 1}}-\frac{F_{D} u_{p}}{c_{p j} T_{j 1}}\right]-\frac{u_{j 2}^{2}}{2 c_{p j} T_{j 1}}
$$

where

$$
\frac{u_{j 1}^{2}}{2 c_{p j} T_{j 1}}=\frac{\gamma-1}{2} M_{j 1}^{2}
$$

and

$$
\frac{u_{j 2}^{2}}{2 c_{p j} T_{j 1}}=\left(\frac{u_{j 2}}{u_{j 1}}\right)^{2}\left(\frac{\gamma-1}{2}\right) M_{j 1}^{2}
$$

\section{Effective Jet Density}

The density ratio is evaluated from

$$
\rho_{j 2} / \rho_{j 1}=T_{j 1} / T_{j 2}
$$

\section{Effective Jet Mach number}

An expression for the effective jet Mach number is given by

$$
\frac{M_{j 2}}{M_{j 1}}=\left(\frac{u_{j 2}}{u_{j 1}}\right)\left(\frac{\rho_{j 2}}{\rho_{j 1}}\right)^{1 / 2}
$$




\section{Effective Jet Exit Area}

The effective jet exit cross sectional area becomes

$$
\frac{A_{j 2}}{A_{j 1}}=\left(\frac{\rho_{j 2}}{\rho_{j 1}}\right)\left(\frac{u_{j 1}}{u_{j 2}}\right)\left(1+\eta \frac{m_{w}}{m_{j 1}}\right)
$$

\section{Droplet Drag and Heat Transfer}

\section{Droplet Drag}

The total drag on the droplet is comprised of both skin friction drag and form drag. Evaporation reduces the skin friction drag due to thickening of the boundary layer, and alters the form drag by displacement of the point of separation of the boundary layer. Additionally, it introduces property variations in the gaseous phase. Similarity considerations based on boundary layer theory suggest that the friction coefficient depends on the Spalding transport parameter $B$ defined by (Kays and Crawford [25])

$$
B=\frac{c_{p g}\left(T_{g}-T_{d}\right)}{h_{f g}\left(T_{d}\right)}
$$

Since the magnitude of the form drag is comparable with friction drag, strictly speaking the drag coefficient in the presence of evaporation cannot be approximated by relations based on boundary layer type theories alone (Sirignano [21]). In the present work the drag coefficient $C_{D}$ in the presence of evaporation is obtained from a relation due to Eisenklam et al. [26], based on measurements on freely falling drops (water, heptane, pentane, ethyl alcohol, etc.), as

$$
C_{D}=C_{D 0} /(1+B)
$$

It was shown in [26] that the factor $(1+B)$ in Eq. (21) has some theoretical basis with regard to considerations of laminar boundary layer on a body of revolution. This relation has been widely considered, for example, by Mastanaiah and Ganic [27] for two-component air-water dispersed flow heat transfer, Sirignano [21] for spray cooling, and recently by Dupays et al. [28] for reactive two-phase flow in solid rocket motors. The above equation suggests that the drag coefficient in the presence of evaporation decreases with an increase in the evaporation rate.

The correlation for the drag coefficient in the absence of evaporation $C_{D 0}$ appearing in Eq. (21), is obtained from White [21] as 


$$
C_{D 0}=\frac{24}{\operatorname{Re}_{p}}+\frac{6}{1+\operatorname{Re}_{p}^{0.5}}+0.4
$$

The effect of Mach number (compressibility) on the droplet drag is not however accounted for. The first term in Eq. (22) represents the Stokes drag [29] valid for Reynolds numbers less than one.

\section{Droplet Heat Transfer and Evaporation}

The fraction of the injected liquid that is evaporated is determined as follows. The heat transferred from the gas to the droplets is given by

$$
q_{p}=N_{p} N u \pi k d_{p}\left(T_{j e}-T_{p}\right)
$$

where $N_{p}$ is obtained from Eq. (10). The quantity $T_{j e}$ is called here the equivalent gas temperature, which will be discussed a little later.

The drop Nusselt number $\mathrm{Nu}$ for an evaporating droplet is computed as follows. With a Couette flow approximation (zero Reynolds number limit), it has been shown that for constant properties the Nusselt number in the presence of evaporation (mass transfer cooling or transpiration) can be shown to be expressed by (Kays and Crawford [25]

$$
N u_{d}=N u_{d 0} \ln (1+B) / B
$$

where $N u_{0}$, denoting the drop Nusselt number in the absence of mass transfer. Strictly speaking, the above relation based on boundary layer type theory does not hold in the near wake of the droplet (Sirignano [21]). Since most of the heat and mass transport for the droplet Reynolds number of interest (order of 100 or less) occurs before the point of separation, vaporization can be satisfactorily predicted by the above relation [21]. This relation has been considered by Mastanaiah and Ganic [27] and Sirignano [21]. The quantity $N u_{0}$ is expressed by the well-known Ranz-Marshall correlation [30]

$$
N u_{0}=2+0.6 \operatorname{Re}_{p}^{0.5} \operatorname{Pr}^{0.33}
$$

The heat of evaporation for the droplets is provided from

$$
q_{p}=\eta \dot{m}_{w} h_{f g}
$$


Since the droplet is assumed to be at the saturation temperature $T_{\text {sat }}$, heat transfer to the droplet is entirely used to vaporize droplet (no sensible heating).

From Eqs. (23) and (26), we find an expression for the evaporation fraction $\eta$ as

$$
\frac{1}{\eta}=1+\frac{\operatorname{Pr}}{N u} \frac{\operatorname{Re}_{j 1}}{\left(\frac{d_{j 1}}{d_{p}}\right)^{2}} \frac{1}{\frac{3}{2}\left(\frac{\rho_{j 1}}{\rho_{p}}\right) n}\left[\frac{h_{f g}}{c_{p j}\left(T_{j e}-T_{s a t}\right)}\right]
$$

where $\operatorname{Pr}$ is the Prandtl number of the gas (taken as 0.7). Eq. (27) suggests that the evaporation factor $\eta$ is independent of the water to jet mass flow rate ratio. This result is believed to be expected since the droplet concentration is relatively small such that droplet interaction is negligible.

The equivalent gas temperature $T_{j e}$ in Eq. (27) is chosen to ensure that $T_{j e} \gg T_{s a t}$ so that the evaporation is heat transfer controlled. In the present work a value of $T_{j e}=1389 \mathrm{~K}$ is considered, which compares with $T_{s a t}=$ $373 \mathrm{~K}$ (saturation temperature of water at atmospheric pressure). It is tacitly assumed that the chosen value of $T_{j e}$ partly accounts for vaporization by mass diffusion.

\section{E. Invariant Groups}

An examination of Eqs. (12), (13) and (27) suggests that the following invariant groups appear in the analysis:

$$
\begin{gathered}
\left.\frac{\operatorname{Re}_{j 1}}{\left(d_{j 1} / d_{p}\right)^{2}} \frac{1}{\rho_{j 1} / \rho_{p}}\right)=c_{1} \\
\frac{\operatorname{Re}_{p}}{\operatorname{Re}_{j 1}}\left(\frac{d_{j 1}}{d_{p}}\right)=c_{2}
\end{gathered}
$$

and

$$
\left(\frac{\rho_{j 1}}{\rho_{p}}\right)\left(\frac{d_{j 1}}{d_{p}}\right)^{3} \frac{\operatorname{Re}_{p}}{\operatorname{Re}_{j 1}^{2}}=c_{3}
$$

$$
c_{2}=c_{1} c_{3}
$$

it is evident that two independent relations exist for the estimation of $\mathrm{Re}_{p}$ and $d_{j 1} / d_{p}$. These are now evaluated as

$$
\left.\frac{d_{j 1}}{d_{p}}=\left[\frac{1}{c_{1}} \frac{\operatorname{Re}_{j 1}}{\left(\rho_{j 1} / \rho_{p}\right.}\right)\right]^{1 / 2}
$$




$$
\operatorname{Re}_{p}=c_{2} \frac{\operatorname{Re}_{j 1}}{\left(d_{j 1} / d_{p}\right)}
$$

Thus the unknown quantities $\operatorname{Re}_{p}$ and $d_{j 1} / d_{p}$ are determined in terms of the adjustable constants $c_{1}$ and $c_{2}$. In view of the complexity with regard to the knowledge of droplet diameter and drop Reynolds number, it is postulated here that the constants $c_{1}$ and $c_{2}$ are invariant. These constants may be established by a correlation with available test data.

\section{F. Drop Characteristics}

In view of the critical role of the drop size in the present investigation, we briefly present a review of the physical processes that control the drop characteristics in systems involving sprays and atomization (Sirignano [21]).

\section{Drop Deformation and Drop Breakup}

The physical processes of drop deformation and breakup are extremely complex (Hsiang and Faeth [31]. According to the classical description of drop breakup, atomization occurs by primary breakup near the liquid surface followed by secondary breakup. Two types of primary drop breakup are generally observed: bag breakup (deformation initiated near the upstream end of the drop), and shear breakup (liquid shearing at the periphery of the drop). Multimode breakup is also present. The breakup processes are not instantaneous.

Hinze [32] demonstrated that the primary breakup regime transitions are primarily dependent on the Weber number We and the Ohnesorge number Oh defined by

$$
W e=\rho\left|u_{d}-u_{g}\right|^{2} d_{p} /(2 \sigma), \quad O h=\mu_{d} /\left(\rho_{d} d_{p} \sigma\right)^{1 / 2}
$$

The secondary breakup is correlated in terms of Eotos number $E_{0}$ (also known as Bond number $B o$ ) defined by [31]

$$
E o=a_{d} \rho_{d} d_{0}^{2} / \sigma
$$

where $a_{d}$ denotes the drop acceleration. Results show that the secondary breakup is not a localized process, but extends over a significant region of about $\mathbf{4 0}$ drop diameters.

Measurements suggest that the critical Weber number $W e_{c r}$ required for the onset of drop breakup (transition criterion for breakup under steady disturbances) is given by (Faeth [20]; Hsiang and Faeth [31])

$$
W e_{c r}=\operatorname{Re}_{c r}^{1 / 2} / 2
$$

where $\operatorname{Re}_{c r}$ is the critical Reynolds number of the drop. 


\section{Drop Size}

On account of the shearing action between the gas and the drop, drops breakup quickly from their initial size near the injector station to a few microns downstream of the injection station (Krothapalli et al. [8]). Turbulence in the gas phase could be influenced by the presence of the droplets. Turbulence in the gas phase is generally reduced by the injection of droplets [8]. Measurements of Krothapalli et al. [8] suggest that the arithmetic mean diameter remain fairly uniform across the jet.

\section{G. Jet Mixing Noise Reduction}

Once the effective jet conditions (velocity, temperature and Mach number) are obtained, the reduction in the jet turbulent mixing noise is evaluated with the aid of the scaling laws proposed by the author $[33,34]$. In these references, the turbulent mixing noise reduction is presented as a function of the jet Mach number and the jet to ambient temperature ratio (see Fig. 2) in both subsonic and supersonic flow. The scaling laws are validated with test data in [34]. A brief account of the scaling laws and the associated assumptions on which the mixing noise reduction has been evaluated is briefly summarized as follows.

Based on dimensional arguments and the theories of Lighthill [35,36], Ffowcs-Williams [37] and Ribner [38 ], and experimental data on cold and hot jets in subsonic and supersonic flow, a scaling law for the mean square sound pressure for subsonic and perfectly expanded supersonic jets as follows [33,34].

$$
\frac{\overline{p^{2}(\theta, f)}}{\left(\rho_{j} u_{j}^{2}\right)}=K_{1}\left(\frac{\rho_{\infty}}{\rho_{j}}\right)\left(\frac{u_{j}}{c_{j}}\right)^{3.5}\left(\frac{c_{j}}{c_{\infty}}\right)^{3.5} G_{1}\left(M_{c}, \theta\right) G_{2}\left(\frac{f}{f_{p}}, M_{c}, \theta\right)
$$

In the above equation, the quantity $K_{1}$ is a proportionality constant, $G_{1}$ is the directivity factor (owing to source convection), and $G_{2}$ accounts for the spectral distribution of the sound power. The quantity $M_{c}$ refers to the convective Mach number (related to the jet Mach numer), $\theta$ the angle from the downstream jet axis, $f_{p}$ the peak frequency. In the scaling law for jet noise proposed above, the effect of jet temperature is accounted for by Lighthill's suggestion through the changes in the density factor in the quadrupole noise field.

The directivity factor is essentially the same as provided by the Lighthill-Ffowcs Williams-Ribner formulation given by 


$$
G_{1}=\left[\left(1-M_{c} \cos \theta\right)^{2}+\alpha M_{c}^{2}\right]^{-5 / 2}
$$

where $\alpha=0.4$ is considered. A generalized similarity spectrum (semi-empirical) is also proposed to account for both the fine scale and the turbulence structure associated with Mach wave radiation as:

$$
G_{2}=\frac{\left(f / f_{p}\right)^{5 / 4 a}}{\left.1+\left(f / f_{p}\right)^{2}\right]^{9 / 6 a}}
$$

where

$$
a=\left\{0.2+\exp \left[-2 M_{c} / \sin (\theta / 2)\right]\right\}^{0.35}
$$

In the author's recent work [34], the scaling laws proposed were validated with test data for OAPWL, OASPL, directivity and spectral content over a wide range of temperature and jet Mach number. Fig. 2 shows that at a given $M_{j}$ the OAPWL depends only on the temperature ratio. For convenience, the data are plotted with reference to OAPWL at $M_{j}=1$ and $T_{j} / T_{\infty}=1$ (isothermal jet). As is to be expected, the OAPWL transitions from a $u_{j}^{8}$ dependence in subsonic flow to $u_{j}^{3}$ at large supersonic Mach number. Referring to the isothermal jet, an increase of sound power of about $56 \mathrm{~dB}$ is predicted as the jet Mach number is increased form 0.2 to 1.0 . Although the calculations are shown for jet Mach numbers of up to 10, they should be viewed with caution for jet Mach numbers in excess of about 5 (hypersonic flow) where real gas effects (including dissociation ) can become significant.

According to the early work of Lush [39] and Fisher et al. [40], there are drastic differences between the predictions based on Lighthill-Ffowcs Williams formulations and the test data. There exists considerable debate on several aspects with regard to the differences between cold and hot jets; this situation is so in spite of the existence for two or three decades of theories of jet noise accounting for temperature effects, which can be improved with reference to the more recent experimental data. The development of CAA (Computational Aeroacoustics), perhaps in conjunction with large eddy simulation (LES) [41-43] can be a further tool in understanding the differences between cold and hot jets.

With regard to the spectral distribution of turbulent mixing noise reduction, the author [44] has proposed an extension of the theory of Temkin and Dobbins [17] for dilute suspensions with nonlinear particle relaxation 
(particle momentum and heat transfer). Satisfactory comparison is shown between the prediction and the data of Norum [7] for the spectral attenuation of sound.

\section{Results and Comparison}

The above analysis suggests that the effective jet conditions in the presence of water injection are dependent primarily on the water-to-gas mass flow rate ratio, and independent of momentum flux ratio, which governs primarily the penetration depth of the injected water normal to the jet. A correlation of the analysis with the test data of Norum [7] for hot supersonic turbulent mixing noise reduction at $M_{j}=1.45$ yields the values of the invariants $c_{1}$ and $c_{2}$ as

$$
c_{1}=5, \quad c_{2}=0.05
$$

Thus in all the results presented below, the above values of the invariants are considered. Details of the evaluation of these constants are provided in section B.

\section{A. Predictions for the Effective Jet Conditions}

Fig. 3a displays the variation of fractional evaporation $\eta$ as a function of the jet Reynolds number for various jet temperatures, as given by eq. (27). It is seen that evaporation increases with an increase in jet Reynolds number and an increase in jet temperature, as is to be expected. The variation of $\eta$ with the jet temperature is illustrated in Fig. 3b.

Fig. 4a shows the variation of the effective jet velocity with the water mass flow rate ratio at $\operatorname{Re}_{j 1}=10^{7}$. The effective jet velocity decreases with an increase in water flow rate on account of the momentum transfer between the gas and the droplets. For mass low rate ratios beyond about four, the rate of decrease in the jet velocity is relatively small. This result seems to be consistent with the experimental observation of Zoppellari and Juve [5], which suggests that beyond a mass flow rate ratio of about four, further reduction in jet noise are not appreciable.

The variation of the effective jet temperature with the water flow rate is displayed in Fig. $4 \mathrm{~b}$ for various jet exit Mach numbers at $\operatorname{Re}_{j 1}=10^{7}$. The effective jet temperature decreases with an increase in water flow rate due to heat transfer from the gas to the droplets and subsequent evaporation. The rate of decrease in the effective jet temperature begins to slow for water flow rate ratios beyond about four, as in the case of the effective jet velocity. At a given mass flow rate ratio, the effective jet temperature decreases with an increase in the jet exit Mach number. A 
crossover trend with the exit Mach number is noted at a flow rate ratio of about 0.6 . This trend may be physically explained as follows. At low water mass flow rate ratio, the term in the denominator of Eq. (15) remains close to unity, so that at a given $\operatorname{Re}_{j 1}$ the ratio $T_{j 2} / T_{j 1}$ increases as $M_{j 1}$ increases. On the other hand, for relatively large values of water mass flow rate ratio, the drag related term becomes appreciable, so that at a given $\operatorname{Re}_{j 1}$, the ratio $T_{j 2} / T_{j 1}$ decreases with increasing $M_{j 1}$.

Illustrated in Fig. $4 \mathrm{c}$ is the dependence of the effective jet Mach number as a function of the water mass flow rate at $\operatorname{Re}_{j 1}=10^{7}$. The results suggest that below a water flow rate ratio of one, the effective jet temperature is almost independent of the jet exit Mach number. This trend is to be expected since at low water mass flow rate ratios less than about one, the changes in the gas temperature across the control volume are not appreciable relative to the velocity changes (see Fig. 4a and 4b). Thus the effective jet Mach number is primarily dependent on the effective jet velocity, which in turn is independent of jet exit Mach number

Fig. $4 \mathrm{~d}$ depicts the distribution of the effective jet density with the water mass flow rate at various jet exit Mach numbers at $\operatorname{Re}_{j 1}=10^{7}$. It is seen that the effective jet density increases with the flow rate, and with an increase in the jet exit Mach number. Calculations suggest that the jet cross sectional area increases with the water flow rate (Fig. 4e). At a fixed flow rate ratio, the effective jet area decreases with an increase in the jet exit Mach number.

The effect of jet exit Reynolds number on the distribution of effective jet velocity, jet temperature and jet Mach number are indicated in Figs. 5a-c. Fig. 5a suggests that the change in the effective jet velocity is relatively small for a three orders of magnitude change in the jet exit Reynolds number. A similar trend is noted with regard to the dependence of jet exit temperature and jet Mach number on the jet exit Reynolds number (Figs. $5 \mathrm{~b}$ and 5c).

These results for the variation of the effective jet conditions suggest that the theory of invariant groups formulated here (in terms of the constants $c_{1}$ and $c_{2}$ ) seems to provide a satisfactory first step in our understanding of the role of water injection in reducing the jet velocity and jet temperature.

It should be cautioned that the present results would entail error at relatively high water flow rate in view of the parasitic noise generation due to water impact. 


\section{B. Comparisons with Experimental Data}

A comparison of the present theory with the test data of Norum ${ }^{7}$, from which $c_{1}$ and $c_{2}$ are determined, is presented in Fig. 6. The data correspond to hot supersonic jet of air from a convergent-divergent (CD) nozzle operation at $T_{t}=867 \mathrm{~K}$, and $M_{j}=1.45$. The jet exit Reynolds number $\operatorname{Re}_{j 1}$ is about $1.3 \times 10^{6}$. At this condition, supersonic jet mixing noise dominates upstream noise radiation, and Mach wave radiation dominates the downstream noise radiation. In the data, water is injected at 45 deg., and the number of injectors includes 6,12 and 18. The data shown correspond to maximum noise reductions with water injection. There is scatter in the data for OASPL reduction at a given water mass flow rate ratio. Thus the data shown here represent averaged values.

In the data of Norum [7], acoustic measurements are made for angles $\theta$ between $30^{\circ}$ and $135^{\circ}$ to the jet downstream axis (total of 28 microphones evenly distributed). At the Mach number of $M_{j}=1.45$ under consideration, upstream noise radiation is dominated by supersonic jet mixing noise, and downstream noise by Mach wave radiation. Data for the maximum noise reduction with mass flow rate ratio is presented. The reduction is more or less evenly distributed across frequency, with a maximum reduction of $3.8 \mathrm{~dB}$ achieved in the upstream direction (of $135^{\circ}$ ), with about $1 \mathrm{~dB}$ reduction accomplished in the peak radiation direction. The spectra and directivity of OASPL reductions are shown only for the highest mass flow rate ratio. Thus the test data correspond primarily to $135^{\circ}$ to the jet downstream axis. The correlation of the present theory with the data for the evaluation of the constants $c_{1}$ and $c_{2}$ is carried out for the upstream direction and only at the highest mass flow rate. These constants are considered for the estimation of noise reduction at other flow rates, and the validity of the theory is thereby tested.

For the test conditions considered above, the present theory suggests that $\eta=0.49$, indicating that 49 percent of $\dot{m}_{w}$ is evaporated within the control volume chosen. At these conditions the present theory yields $\operatorname{Re}_{p}=2.1$ and $d_{j 1} / d_{p}=3.13 \times 10^{4}$, as obtained form eqs. (31a) and (31b). The agreement between the present prediction and the data is seen to be favorable, considering the complexity of the problem, and the number of simplifying assumptions made in the analysis. Both the data and the theory suggest that the reduction in mixing noise increases with an increase in water flow rate. At the highest water flow rate considered in the data, a reduction of $3.8 \mathrm{~dB}$ in the mixing 
noise is achieved. Calculations show that the noise reduction is primarily achieved by jet velocity reduction through momentum transfer, while the jet temperature reduction is small enough to contribute appreciable noise reduction.

\section{Discussion}

The invariants postulated here are applicable to the control volume only, and are not applicable to the entire flowfield since the shear layers dominate the flowfield relative to the potential core. This paper is concerned primarily with conditions in the neighborhood of the nozzle exit with regard to the determination of the effective jet conditions. The author believes that the assumptions and the invariant postulate are reasonable and valid. The principal objective of the present work is to understand the mechanisms of noise reduction with regard to the particulate relaxation processes. A sophisticated numerical analysis based on Navier-Stokes CFD and CAA [4143] would be helpful, but is outside the scope of the present study.

A distinction could be made between water injection systems and microjet injection as follows. Experimental data of Krothapalli et al. $[8,9,10,16]$ with microjets, and the data with higher mass flow rate ratio such as those of Norum [7], in conjunction with the recent theory, suggest that a water mass flow rate ratio of about 0.05 to 0.1 is representative of the boundary between water microjet injection and water injection. Water microjet injection reduces jet noise by reducing turbulent jet mixing noise and mitigating Mach wave radiation, which is regarded as momentum ratio effect, as observed by the measurements of Greska and Krothapalli [9]. This momentum ratio parameter $J$ is defined by

$$
J=\frac{\rho_{m j} u_{m j}^{2}}{\rho_{j} u_{j}^{2}}
$$

where the subscript $m j$ refers to microjet.

Microjets have been shown to result in a moderate noise reduction primarily due to the reduction of turbulence levels and the alteration of the shock structure (and the associated shock-turbulence interaction), see Krothapalli et al. [8]. The data of Greska and Krothapalli [9] indicate that in the presence of shock waves, the noise reduction with the aid of microjet injection could be satisfactorily correlated by the momentum ratio parameter.

The manner in which the region covered by the control volume (covering only the first two downstream diameters) affects the turbulence at the end of the potential core (which, according to eq. (7), is approximately 8.3 diameters downstream for the $M_{j}=1.45$ example considered) is explained as follows. Measurements by 
Krothapalli et al. [8] in a Mach 1.4 nozzle suggest that the presence of water droplets in the jet modified the turbulence structure significantly, resulting in axial and normal rms velocity fluctuations (transverse turbulence intensity) of about 10 percent and 30 percent respectively relative to a normal jet (without mass injection). At low mass flow rate ratios of about 0.05 considered in this reference, the mean flow structure (velocity field) remains essentially unaltered by the water injection. Under these circumstances of microjet injection (say, at mass flow rate ratio below about 0.05 ), it is believed that the turbulence reduction due to the breakup of water droplets and the presence of the dispersed phase are responsible for noise suppression. Also the noise reduction levels are spread over all the directions (including the peak radiation direction for Mach wave radiation) and all frequencies.

It is thus seen that for water microjet injection, noise reduction is manifested primarily through a reduction of jet turbulence levels. For water injections at relatively high mass flow rate ratios (say, ratios in excess of about 0.05 to 0.1 ) under consideration in the present work, the jet mean flow structure (velocity and temperature) is changed by the presence of the droplets and their interactions (momentum and heat transport). The attendant changes in turbulence levels and noise modification thereof is perhaps not appreciable, since the mean flow velocity is at the same time diminished by the injection process. Energy from the mean flow to the turbulence may actually be reduced under these circumstances. It should be pointed out however that a detailed account of turbulence modification in the source region due to the droplet presence and interaction with regard to noise reduction is beyond the scope of the present work.

It is to be remarked that the present theory, asserting that the noise reduction may be estimated in terms of two dimensionless invariant groups, has to be confirmed in the future by further comparisons with experimental data.

\section{Conclusion}

The effect of water injection on the turbulent jet mixing noise reduction has been theoretically investigated on the basis of a one-dimensional control volume formulation for the effective jet exit conditions. The theory yields two dimensionless invariant groups, involving the ratio of droplet diameter to jet exit diameter and the ratio of droplet Reynolds number to jet Reynolds number. Correlation of the theory with available data for hot supersonic jet mixing noise reduction provided a satisfactory agreement. The theory predicts the experimental trend that the jet mixing noise reduction increases with an increase in the water mass flow rate. It is demonstrated that above certain mass flow rate ratios (typically exceeding microjet injection levels) the water mass flow rate ratio is an important 
parameter characterizing the mixing noise reduction. The conception of effective jet exit conditions, proposed herein, appears to be a significant first step in our understanding the mechanisms of jet noise reduction due to water injection.

\section{Acknowledgments}

The author would like to thank the referees for their valuable suggestions and criticism that improved the manuscript. 


\section{References}

[1] Crighton, D.G., Orderly structure as a source of jet exhaust noise: Survey lecture, In Structure and Mechanisms of Turbulence II (ed. H. Fiedler), Lecture Notes in Physics, Vol. 76, pp. 154-170, Springer, 1977.

[2] Dougherty, N.S., and Guest, S.H., A correlation of scale model and flight aeroacoustic data for the Space Shuttle vehicle, AIAA-84-2351, AIAANASA $9^{\text {th }}$ Aeroacoustics Conference, Williamsburg, Virginia, October 1984.

[3] Jones, J.H., Scaling of ignition startup pressure transients in rocket systems as applied to the space shuttle overpressure phenomenon, JANNAF 13 ${ }^{\text {th }}$ Plume Technology Meeting, CPIA-PUB-357, Vol. 1, 1982.

[4] Moriniere, V., Gervais, Y., and Peube, J.-L, Numerical calculation of spectrum emission and jet noise reduction by injection of mass, Internoise 95, Newport Beach, pp. 273-276, July 1995.

[5] Zoppellari, E., and Juve, D., Reduction of jet noise by water injection, AIAA-97-1622, 1997.

[6] Zoppellari, E., and Juve, D., Reduction of hot jet noise by water injection, AIAA-98-2204, 1998.

[7] Norum, T.D., Reductions in multi-component jet noise by water injection, AIAA-2004-2976, $10^{\text {th }} A I A A / C E A S$ Aeroacoustics Conference, Manchester, Great Britain, May 2004.

[8] Krothapalli, A., Venkatakrishnan, L., Lourenco, L., Greska, B., and Elavarasan, R., Turbulence and noise suppression of a high-speed jet by water injection, Journal of Fluid Mechanics, Vol. 491, 2003, pp. 131-159.

[9] Greska, B., and Krothapalli, A., Jet noise reduction using aqueous microjet injection, AIAA-2004-2971, $10^{\text {th }}$ AIAA/CEAS Aeroacoustics Conference, Manchester, Great Britain, May 2004.

[10] Washington, D., and Krothapalli, A., The role of water injection on the mixing noise of supersonic jet, AIAA Paper 98-2205, June 1998.

[11] Sewell, C.J.T., On the extinction of sound in a viscous atmosphere by small obstacles of cylindrical and spherical form, Philosophical Transactions of the Royal Society (London), A210, 1910, pp. 239-270.

[12] Epstein, P.S., and Carhart, R.R., The absorption of sound in suspensions and emulsions, I. Water fog in air, Journal of the Acoustical Society of America, Vol. 25, 1953, pp. 553-565. 
[13] Knudsen, V.O., Wilson, J.V., and Anderson, N.S., The attenuation of sound in fog and smoke, Journal of the Acoustical Society of America, Vol. 20, 1948, pp. 849-857.

[14] Marble, F.E., and Wooten, D.C., Sound attenuation in a condensing vapor, Physics of Fluids, Vol. 13, pp. 2657-2664.

[15] Marble, F.E., and Candel, S.M., Acoustic attenuation in fans and ducts by vaporization of liquid droplets, AIAA Journal, Vol. 13, 1975, pp. 634-639.

[16] Krothapalli, A., Venkatakrishnan, Elavarasan, R., and Lourenco, L., Supersonic jet noise suppression by water injection, AIAA-2000-2025, $6^{\text {th }}$ AIAA/CEAS Aeroacoustics Conference, Hlahaina, Hawaii, June 2000.

[17] Temkin, S., and Dobbins, R.A., Attenuation and dispersion of sound by particulate Relaxation Processes, Journal of the Acoustical Society of America, Vol. 40, No. 2, 1966, pp. 314-324.

[18] Dupays, J., and Vuillot, F., Propagation of Acoustic Waves in a two-phase vaporizing mixture, Journal of Propulsion, Vol. 18, No. 1, 2002, pp. 222-224.

[19] Kandula, M., and Lonergan, M., Effective jet properties for the estimation of turbulent mixing noise reduction by water injection, AIAA-2007-3645, 2007.

[20] Faith, G.M., Evaporation and combustion of Sprays, Progress in Energy and Combustion Science, Vol. 9, 1983, pp. 1-76.

[21] Sirignano, W., Fluid Dynamics of Sprays- 1992 Freeman Scholar Lecture, Journal of Fluids Engineering, Vol. 115, pp. 345-378, September 1993.

[22] Eldred, K.M., Acoustic loads generated by the propulsion system, NASA SP-8072, 1971.

[23] Laufer, J., et al., Experiments on supersonic jet noise, AIAA Journal, Vol. 14, No. 4, 1976, pp. 489-497.

[24] Bailly, C., Lafon, P., and Candel, S., Subsonic and supersonic jet noise predictions from statistical source models, AIAA Journal, Vol. 35, No. 11, 1997, pp. 1688-1696.

[25] Kays, W.M., and Crawford, M.E., Convective Heat and Mass Transfer, $2^{\text {nd }}$ ed., McGraw-Hill, New York, 1980.

[26] Eisenklam, P., Anunachalam, S.A., and Weston, J.A., "Evaporation rates and drag resistance of burning drops," in Proceedings of the $11^{\text {th }}$ Symposium (International) on Combustion, The Combustion Institute, Pittsburgh, PA, pp. 715-728, 1967. 
[27] Mastanaiah, K. and Ganic, E.N., "Heat transfer in two-component dispersed flow, Journal of Heat Transfer," Transaction of the ASME, Vol. 103, 1981, pp. 300-306.

[28] Dupays, J., Wey, S., and Fabignom, Y., "Steady and unsteady reactive two-phase computations in solid rocket motors with Eulerian and Lagrangian approaches," AIAA Paper 2001-3871, 2001.

[29] Stokes, G.G., On the effect of internal friction of fluids in motion, Cambridge Philosophical Transactions, Vol. 9, 1851, pp. 8-106.

[30] Ranz, W.E., and Marshall, W.P., Chemical Engineering Progress, Vol. 48, No. 141, 1952, p. 173.

[31] Hsiang, L.-P., and Faith, G.M., Drop deformation and breakup due to shock wave and steady disturbances, International Journal of Multiphase Flow, Vol. 21, No. 4, 1995, pp. 545-560.

[32] Hinze, J.O., Fundamentals of the hydrodynamical mechanism of splitting in dispersion processes, AIChE Journal, Vol. 1, 1955, pp. 289-295.

[33] Kandula, M., and $\mathrm{Vu}, \mathrm{B}$., On the scaling laws for jet noise in subsonic and supersonic flow, AIAA-20042976, $9^{\text {th }}$ AIAA/CEAS Aeroacoustics Conference, Hilton Head, South Carolina, May 2003.

[34] Kandula, M., On the scaling laws and similarity spectra for jet noise in subsonic and supersonic flow, International Journal of Acoustics and Vibration, Vol. 13, No. 1, 2008, pp. 3-16.

[35] Lighthill, M.J., “On sound generated aerodynamically, I. General Theory," Proceedings of the Royal Society A., Vol. 211, 1952, pp. 564-587.

[36] Lighthill, M.J., "On sound generated aerodynamically, I. Turbulence as a source of sound," Proceedings of the Royal Society A., Vol. 222, 1954, pp. 1-32.

[37] Fflowcs-Williams, J.E., "The noise from turbulence convected at high speed," Proceedings of the Royal Society A., Vol. 255, 1963. pp. 469-503.

[38] Ribner, H.S., "A new theory of noise generation, directionality and spectra," Journal of the Acoustical Society of America, Vol. 31, 1962, pp. 245-246.

[39] Lush, P.A., "Measurements of subsonic jet noise and comparison with Theory," Journal of Fluid Mechanics, Vo. 46, part 3, 1971, pp. 477-500.

[40] Fisher, M.J., Lush, P.A., and Harper-Bourne, M., "Jet noise," Journal of Sound and Vibration, Vol. 28, No. 3, 1973, pp. 563-585. 
[41] Bogey, C., Bailly, C., and Juve, D., "Noise investigation of a high subsonic, moderate Reynolds number jet using a compressible LES," Theoretical and Computational Fluid Dynamics, Vol. 16, No. 4, pp. 273-297, 2003.

[42] Bodony, D.J., and Lele, S.K., "Current status of jet noise predictions using large-eddy simulation," AIAA Journal, Vo. 46, No. 2, 2008, pp. 364-380.

[43] Uzun, A., Lyrintzis, A.S., and Blaisdell, G.A., "Coupling of integral acoustic methods with LES for jet noise prediction," International Journal of Aeroacoustics, Vol. 3, No. 4, 2004, pp. 297-346.

[44] Kandula, M., Spectral attenuation of sound in dilute suspensions with nonlinear particle relaxation, accepted for publication in Journal of the Acoustical Society of America, August 2008. 


\section{Captions to Figures}

Fig. 1 Schematic of the jet configuration with water injection.

Fig. 2. Effect of jet Mach number and jet temperature on overall sound power, from Kandula [34].

Fig. 3a Variation of the fractional evaporation with the jet Reynolds number.

Fig. 3b Variation of fractional evaporation with jet temperature.

Fig. 4a Variation of effective jet velocity with the water mass flow rate.

Fig. $4 \mathrm{~b}$ Variation of effective jet temperature with the water mass flow rate.

Fig. 4c Variation of effective jet Mach number with the water mass flow rate.

Fig. 4d Variation of effective jet density with the water mass flow rate.

Fig. 4e Variation of effective jet cross sectional area with the water mass flow rate.

Fig. 5a Dependence of effective jet velocity with jet Reynolds number.

Fig. $5 b$ Dependence of effective jet temperature on jet Reynolds number.

Fig. 5c Dependence of effective jet Mach number on jet Reynolds number.

Fig. 6 Comparison of the predictions with data of Norum (2004) for turbulent mixing noise reduction due to water injection. 


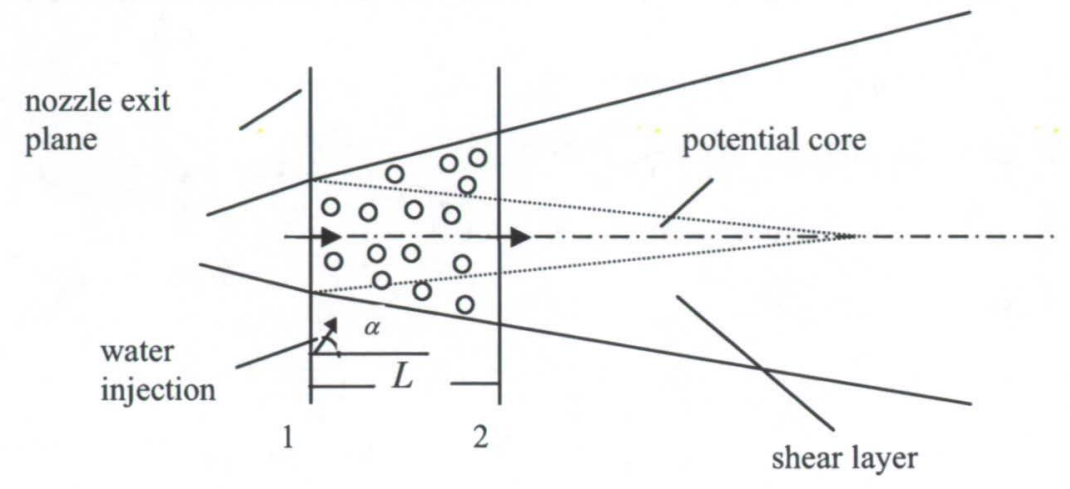

Fig. 1 Schematic of the jet configuration with water injection.

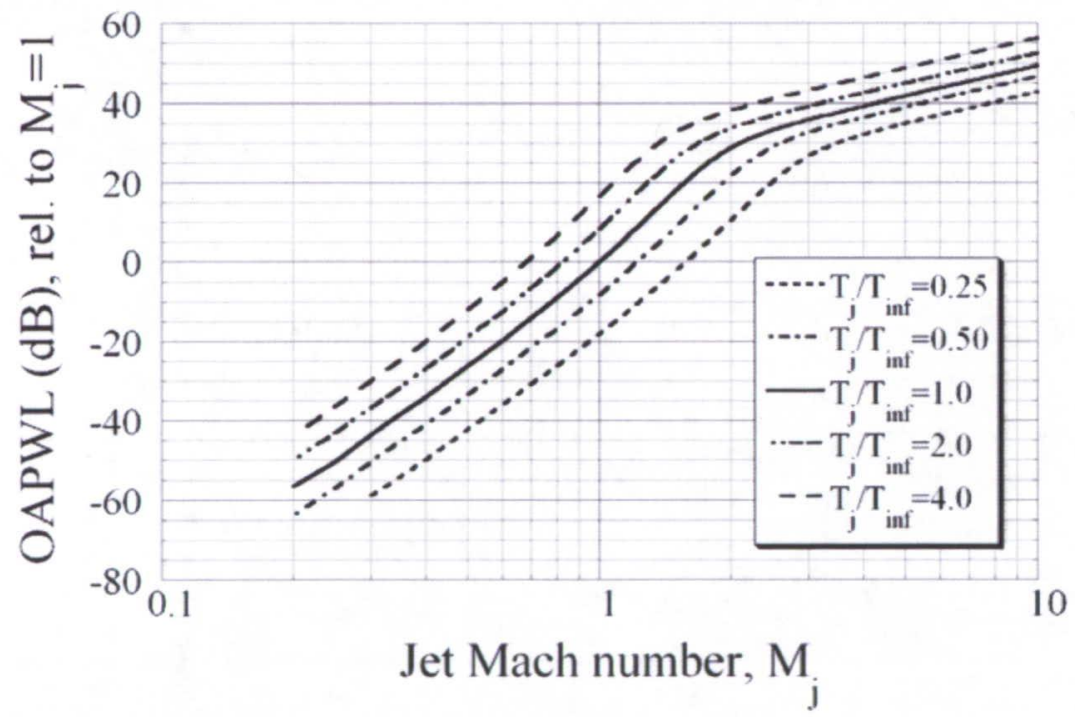

Fig. 2. Effect of jet Mach number and jet temperature on overall sound power, from Kandula [34]. 


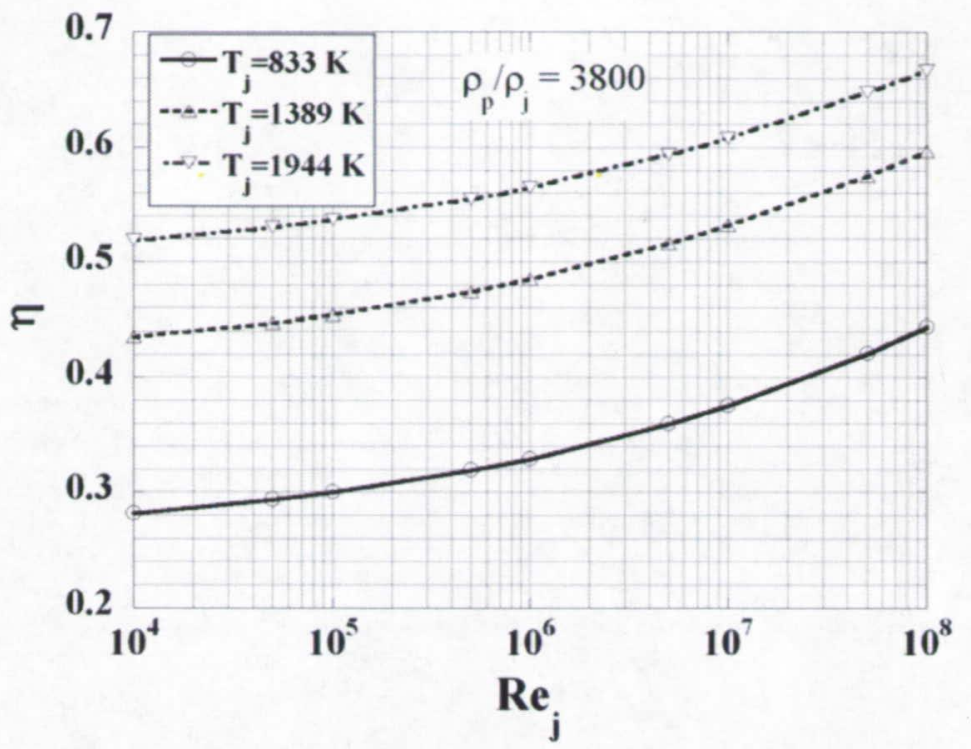

Fig. 3a Variation of the fractional evaporation with the jet Reynolds number.

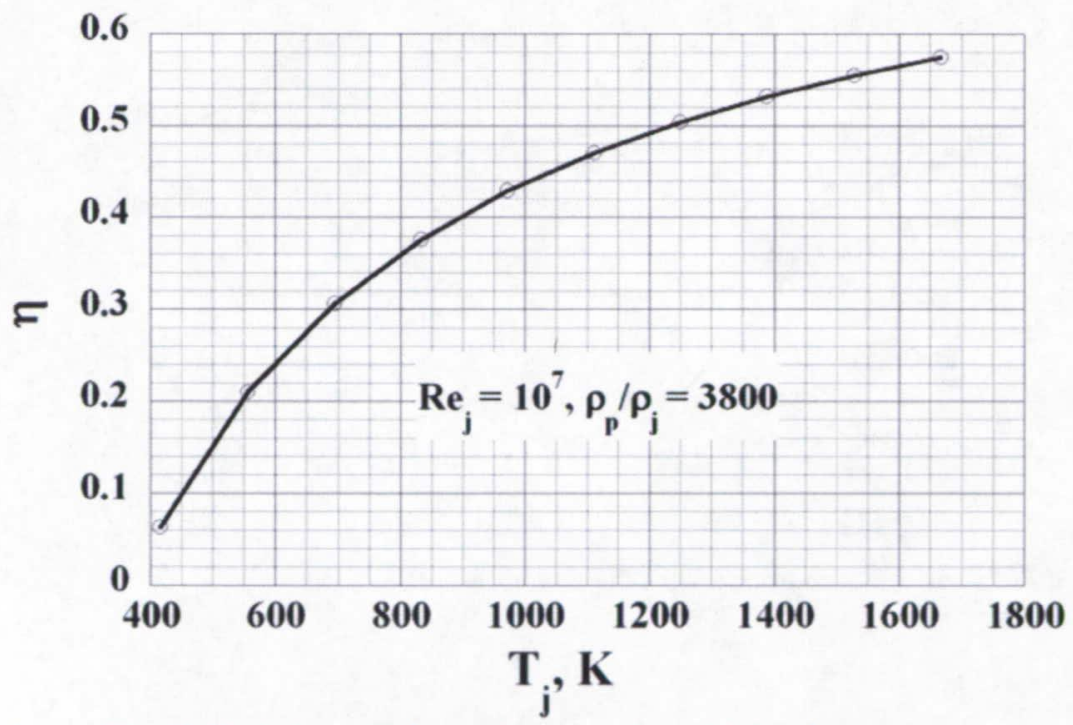

Fig. 3b Variation of fractional evaporation with jet temperature. 


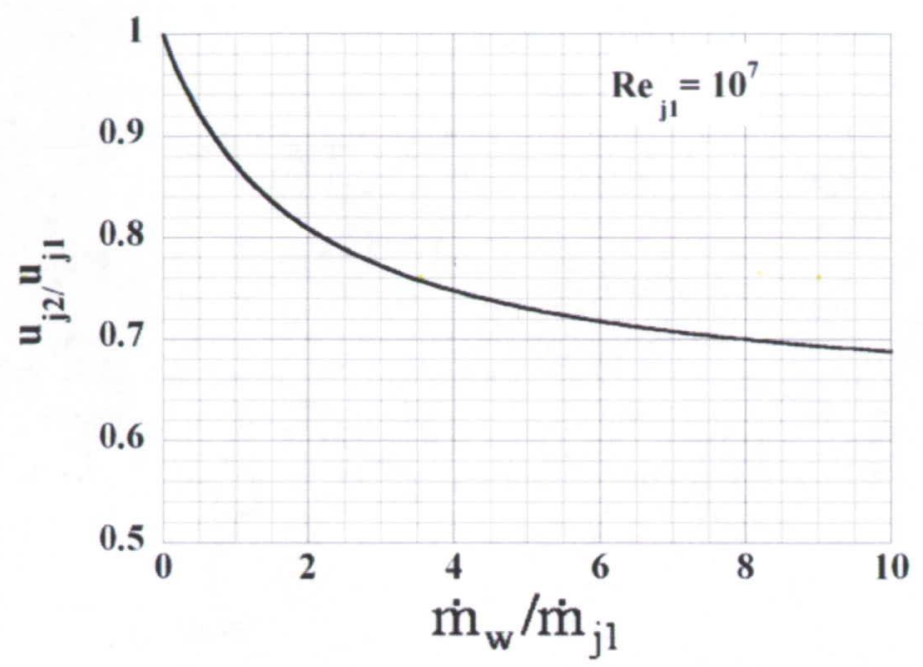

Fig. 4a Variation of effective jet velocity with the water mass flow rate.

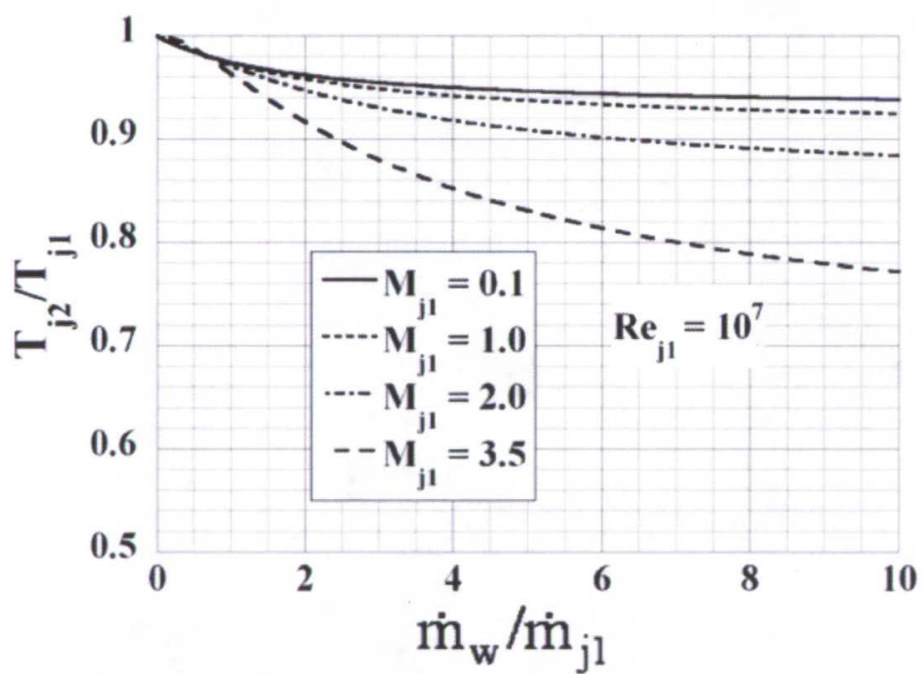

Fig. 4b Variation of effective jet temperature with the water mass flow rate. 


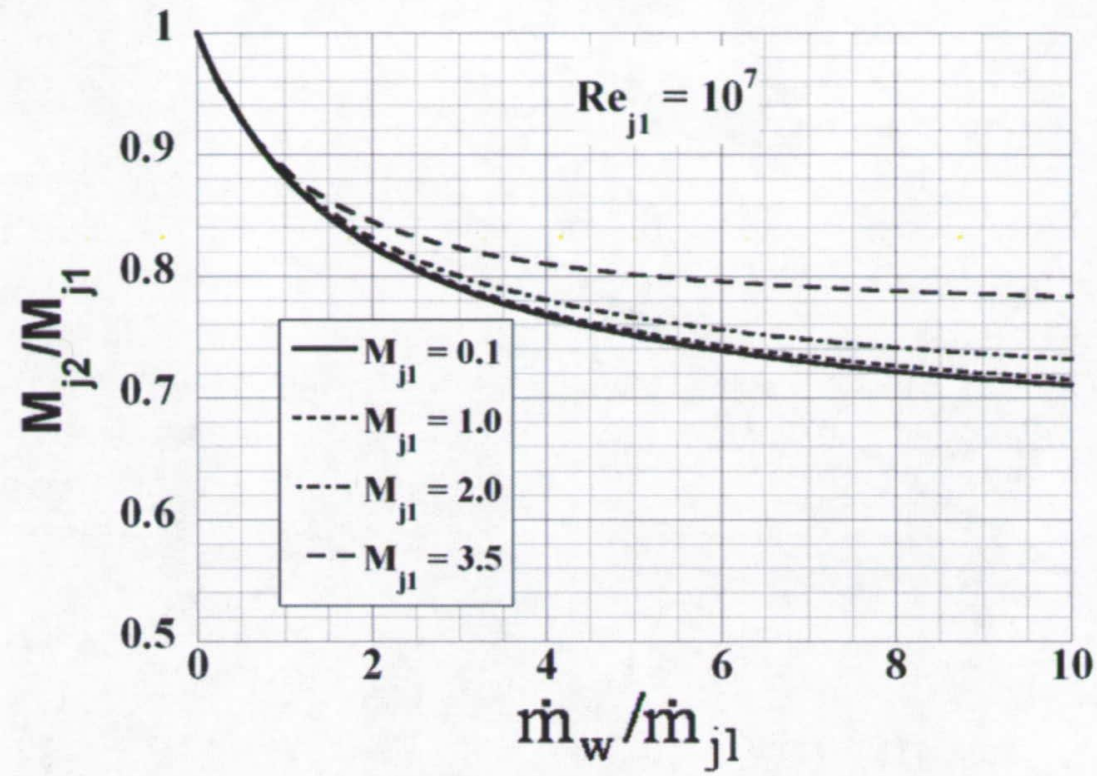

Fig. 4c Variation of effective jet Mach number with the water mass flow rate.

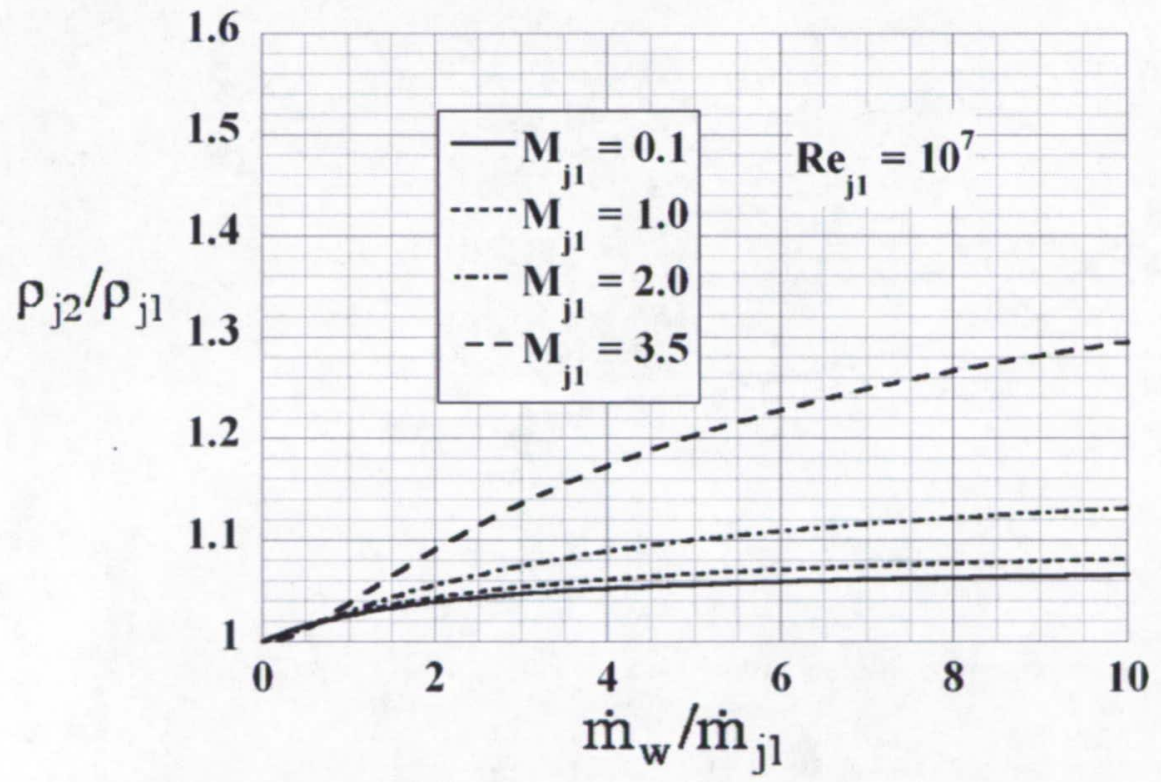

Fig. 4d Variation of effective jet density with the water mass flow rate. 


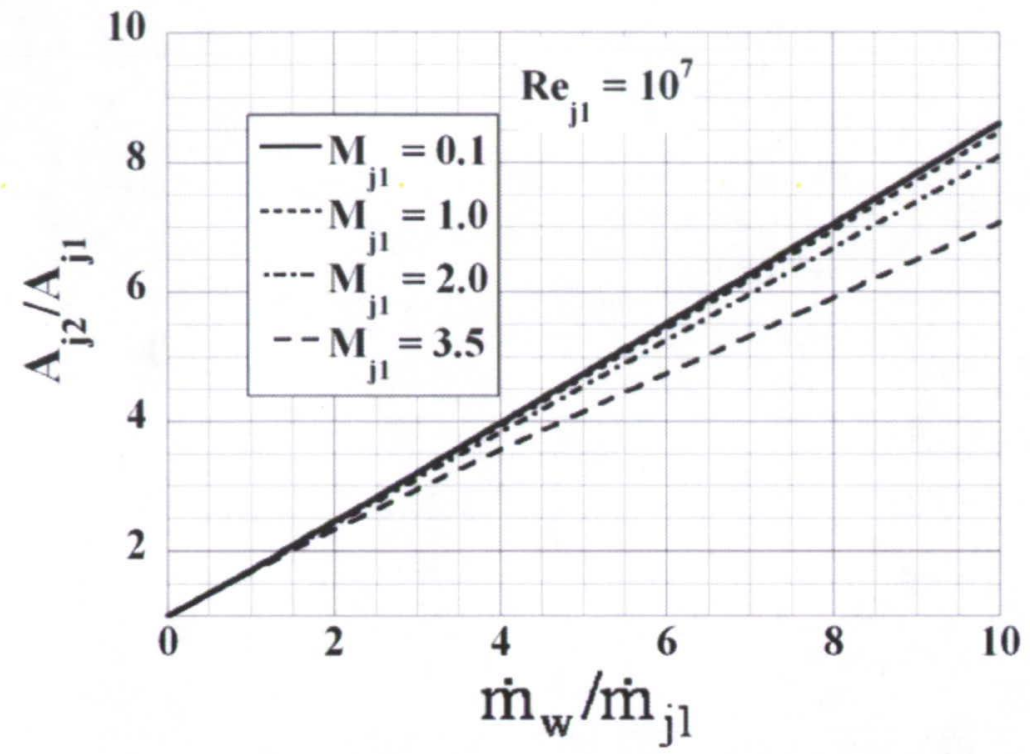

Fig. 4e Variation of effective jet cross sectional area with the water mass flow rate.

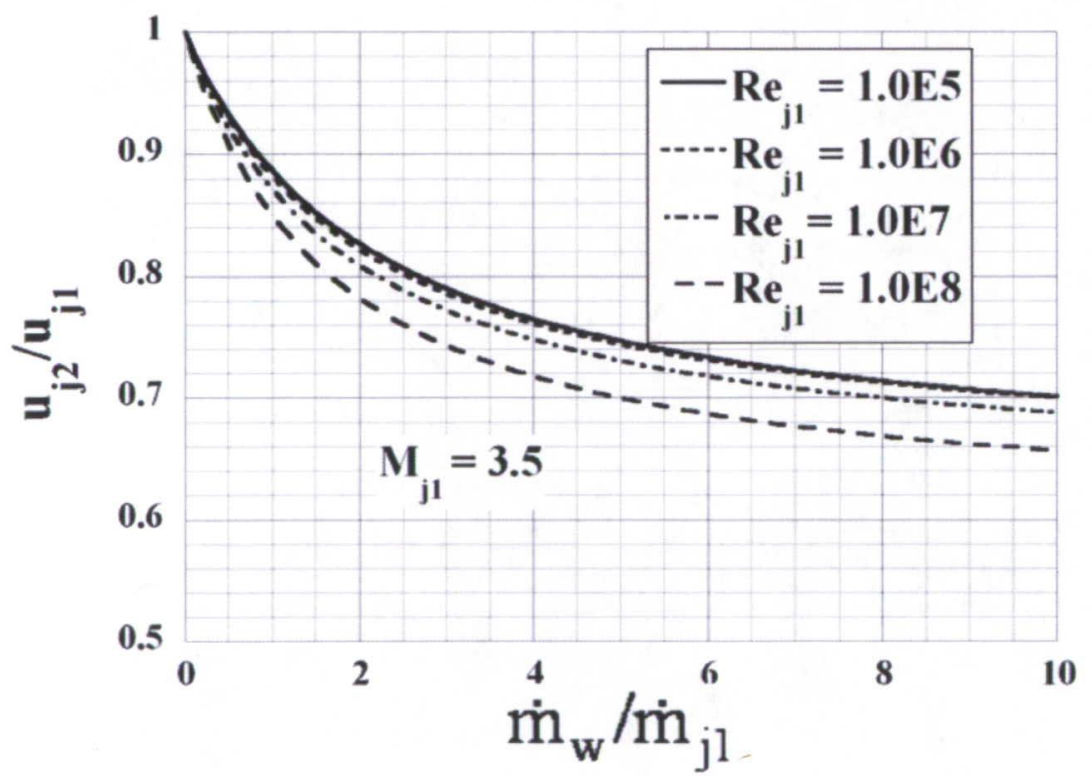

Fig. 5a Dependence of effective jet velocity with jet Reynolds number. 


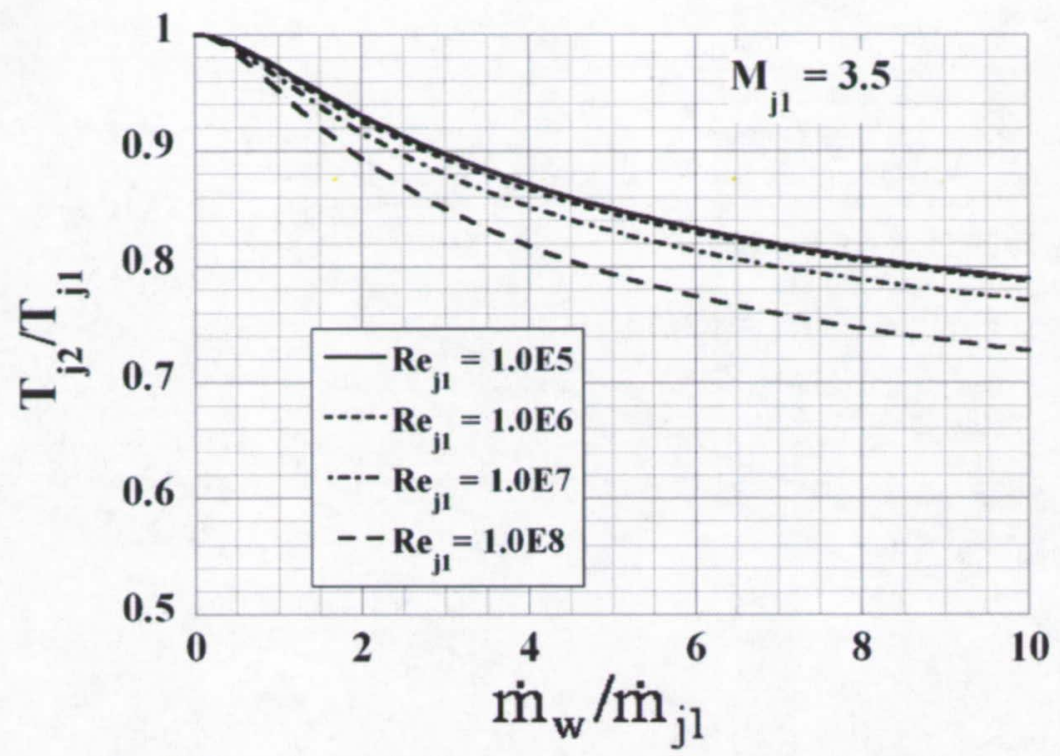

Fig. $5 \mathrm{~b}$ Dependence of effective jet temperature on jet Reynolds number.

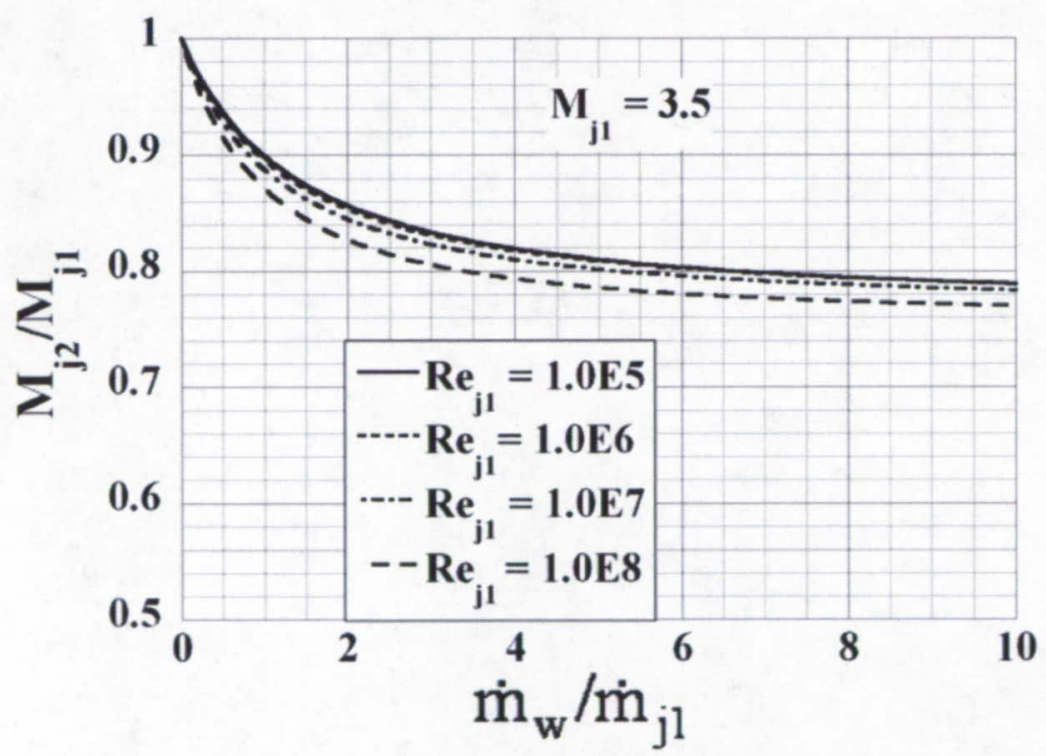

Fig. 5c Dependence of effective jet Mach number on jet Reynolds number. 


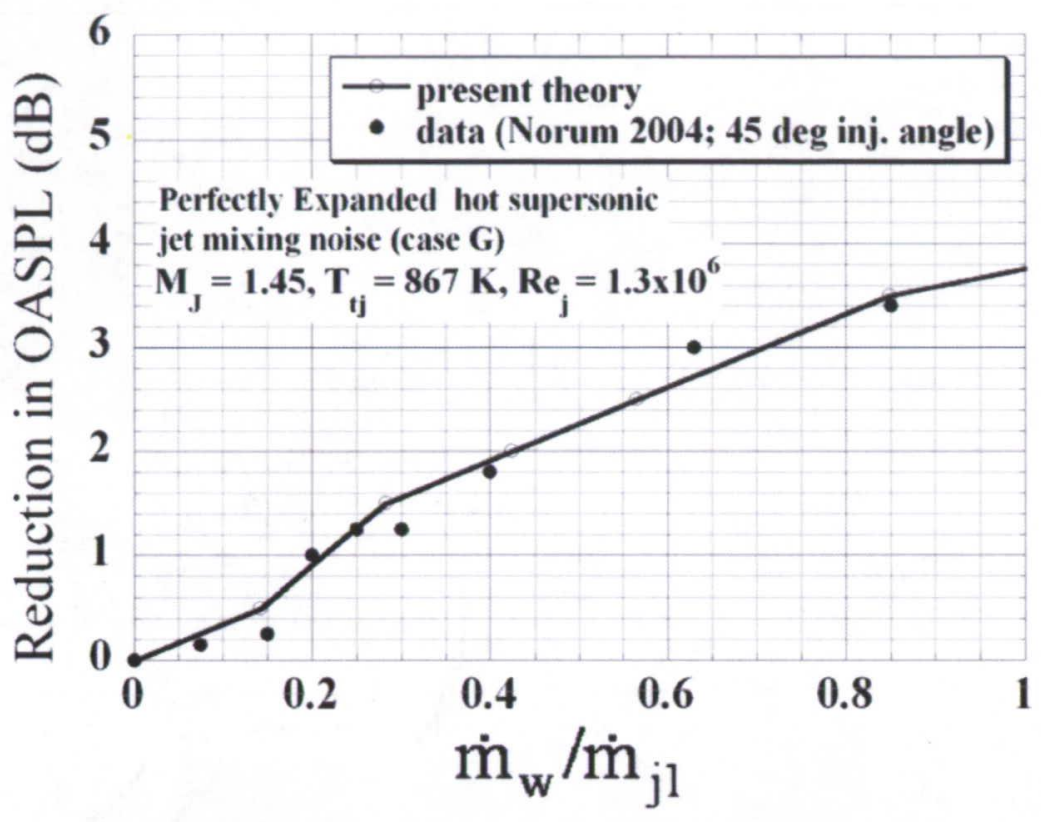

Fig. 6 Comparison of the predictions with data of Norum (2004) for turbulent mixing noise reduction due to water injection. 
The public reporting burden for this collection of information is estimated to average 1 hour per response, including the time for reviewing instructions, searching existing

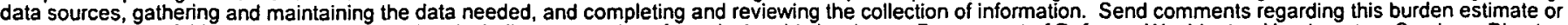

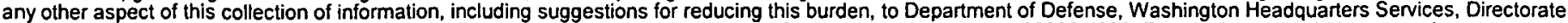
for Information Operations and Reports (0704-0188), 1215 Jefferson Davis Highway, Suite 1204, Arlington, VA 22202-4302. Respondents should be aware that notwithstanding any other provision of law, no person shall be subject to any penalty for failing to comply with a collection of information if it does not display a currently notwithstanding any other

valid OMB control number.
PLEASE DO NOT RETURN YOUR FORM TO THE ABOVE ADDRESS

\begin{tabular}{l|l} 
1. REPORT DATE (DD-MM-YYYY) & 2. REPORT TYPE
\end{tabular}

Journal Article

3. DATES COVERED (From - TO)

\section{TITLE AND SUBTITLE}

Prediction of Turbulent Jet Mixing Noise Reduction by Water Injection

\section{5a. CONTRACT NUMBER}

NAS 10-03006

5b. GRANT NUMBER

5c. PROGRAM ELEMENT NUMBER

5e. TASK NUMBER

\section{AUTHOR(S)}

Kandula, Max 5f. WORK UNIT NUMBER

\section{5d. PROJECT NUMBER}

\section{PERFORMING ORGANIZATION} REPORT NUMBER

\section{PERFORMING ORGANIZATION NAME(S) AND ADDRESS(ES)}

ASRC Aerospace

ASRC-5211

Kennedy Space Center, FL 32899

9. SPONSORING/MONITORING AGENCY NAME(S) AND ADDRESS(ES)

National Aeronautics and Space Administration

$\mathrm{NE}$

Kenndey Space Center, FL 32899
10. SPONSORING/MONITOR'S ACRONYM(S)

NASA KSC

11. SPONSORING/MONITORING REPORT NUMBER

\section{DISTRIBUTION/AVAILABILITY STATEMENT}

\section{SUPPLEMENTARY NOTES}

\section{ABSTRACT}

A one-dimensional control volume formulation is developed for the determination of jet mixing noise reduction due to water injection.

The analysis starts from the conservation of mass, momentum and energy for the control volume, and introduces the concept of effective jet parameters (jet temperaturem jet vlocity, and jet Mach number). It is shown that the water to jet mass flow ratio is an important parameter characterizing the jet noise reduction on account of gas-to-droplet momentum and heat transfer. Two independent dimensionless invariant groups are postulated, and provide the necessary relations for the droplet size and droplet Reynolds number. Results are presented illustrating the effect of mass flow rate ratio on the jet mixing noise reduction for a range of jet Mach mumber and jet Reynolds number. Predictions from the model show satisfactory comparison with available test data on perfectly expanded hot supersonic jets. The results suggest that significant noise reductions can be achieved at increased flow rates.

\section{SUBJECT TERMS}

spectral attenuation

\begin{tabular}{|c|c|c|c|}
\hline \multicolumn{3}{|c|}{ 16. SECURITY CLASSIFICATION OF: } & \multirow{2}{*}{$\begin{array}{l}\text { 17. LIMITATION OF } \\
\text { ABSTRACT }\end{array}$} \\
\hline a. REPORT & b. ABSTRACT & c. THIS PAGE & \\
\hline
\end{tabular}
18. NUMBER 19b. NAME OF RESPONSIBLE PERSON \begin{tabular}{l|l} 
OF & Max Kandula \\
\cline { 2 - 3 }
\end{tabular}

